
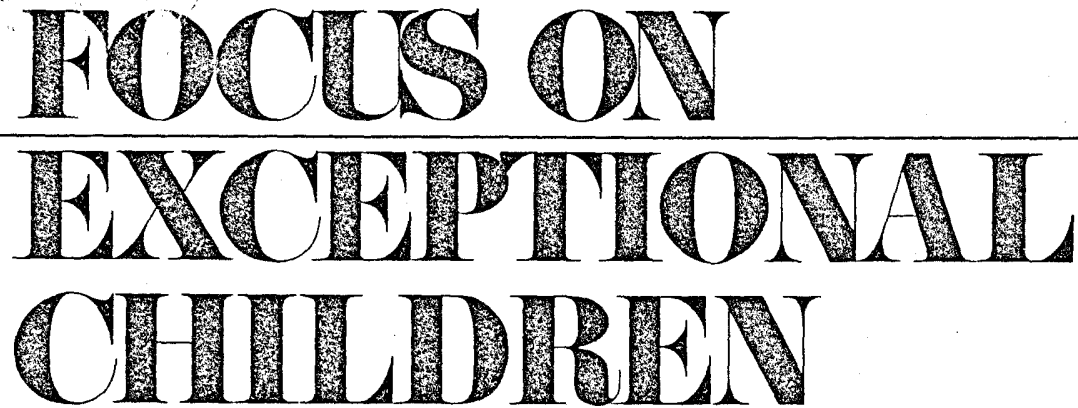

\title{
Curricula and Instructional Procedures for Severely Handicapped Students
}

\author{
Doug Guess and Mary Jo Noonan
}

Educational instruction among severely handicapped students is an effort barely 15 years old. During this brief history, curriculum development has followed several paths in attempting to identify content and methodology that will meet the needs of a population having severe skill deficits, maladaptive behaviors, and slow rates of achievement. After reviewing and analyzing the major curricula and instructional procedures that have evolved from various theoretical positions, we will give some suggestions for redirections in the field.

\section{THE DEVELOPMENTAL APPROACH}

Traditionally, curricula for the severely handicapped have been developmental - designed to replicate the normal sequence of development among handicapped students. Justification for the developmental approach rests on at least three assumptions: 1) normal development constitutes the most logical ordering of behaviors in a curriculum; 2) many behaviors within normal development are prerequisite behaviors; and 3) behaviors acquired at a particular age by a normal child are appropriate objectives for a severely handicapped student at the same level of development (Baldwin, 1976; Haring \& Bricker, 1976; Stephens, 1977). On these premises, a multitude of chronologically sequenced behavior scales have been put forth as curricula for the severely handicapped. These curricula describe the "what to teach" and the order in which it should be taught.

\section{Developmental Scales}

Normal development serves as the outline of content in the developmental curriculum. Content is sequenced within behavior domains (e.g., gross motor, fine motor, language, social, and self-help) that function as both an assessment and the objectives of the curriculum. Because the assessment and objectives are one and the same, the curricula have been referred to as "assessment-linked" (Bricker, Bricker, Iacino, \& Dennison, 1976; Gentry \& Adams, 1978).

Doug Guess is a professor and Mary Jo Noonan a doctoral candidate in the Department of Special Education. University of Kansas. 
As developmental curricula were used increasingly with the severely handicapped, two criteria were applied to evaluate a "good" curriculum: 1) fine increments between behaviors; and 2) a broad scope of content. A curriculum with many items would usually be considered superior to one with fewer items for the same levels of development. The more detailed sequence would be more sensitive to behavior change, and an objective targeted through the assessment would be only a small step from behaviors already within the student's repertoire.

\section{Implementation}

Use of the developmental curriculum begins with assessment. A student is assessed through a checklist of the normally sequenced behaviors. The first item in each content domain that a student cannot demonstrate is targeted as an instructional objective. Most developmental curricula suggest a behavioral, data-based approach for training objectives. These curricula may include task analyses for objectives or examples of systematic programs for training items: Other curricula include more general training activities that correspond to the behavior in each sequence. Overall, the major utilization of a developmental curriculum is in the assessment and targeting of objectives.

FOCUS ON EXCEPTIONAL CHILDREN (ISSN 0015-511X) (USPS 203-360) is published monthly except June, July, and August as a service to teachers, special educators, curriculum specialists, administrators, and those concerned with the special education of exceptional children. This journal is abstracted and indexed in Exceptional Child Education Resources, and is also available in microform from Xerox University Microfilms, Ann Arbor, Michigan. Subscription rates, $\$ 15.00$ per year. Copyright 1982, Love Publishing Company. All rights reserved. Reproduction in whole or part without written permission is prohibited. Printed in the United States of America. Second class postage is paid at Denver, Colorado. POSTMASTER: Send address changes to:

$$
\begin{aligned}
& \text { Love Publishing Company } \\
& \text { Executive and Editorial Office } \\
& 1777 \text { South Bellaire Street } \\
& \text { Denver, Colorado } 80222 \\
& \text { Telephone (303) } 757-2579
\end{aligned}
$$

\section{EDITORIAL BOARD}

Edward L. Meyen University of Kansas
Glenn A. Vergason Georgia State, University

Richard J. Whelan

University of Kansas Medical Center Publisher

\section{Other Considerations}

Proponents of the developmental model have acknowledged that the normal sequence of behaviors may not comprise the complete curriculum for the severely handicapped. In describing the model for preschool severely handicapped, Allen (1978) cautioned against inflexibly adhering to normal sequences, since handicapped children may follow an atypical route of development. An awareness of atypical development as a curricular consideration was expressed by Bricker et al. (1976), who adhere strongly to following the normal sequence but suggest that a "corrective strategy" to decelerate maladaptive and inappropriate behaviors may also be needed.

Modifications of the developmental sequences may at times result in a more appropriate and individualized curriculum. Gentry and Adams (1978), for example, pointed out that in addition to being matched to a student's developmental level, instructional objectives must be immediately useful. Hayden, McGinness, and Dmietriev (1976) described some of these "immediately useful" objectives as "tool skills" - behaviors that are critical for learning more complex skills, such as imitation. An alternative approach for fitting the curriculum to individual needs, discussed by Baldwin (1976), is to modify specific task analyses of objectives by collapsing unnecessary steps or adding steps (branching).

\section{Developmental Curriculum Models}

Many developmental curricula for the severely handicapped are presently available. Some are confined to a single content domain, such as a motor curriculum by Folio and Dubose (1974) and a language program by Bricker, Dennison, and Bricker (1976). Developmental curricula that include many content domains and are frequently used with the severely handicapped have been written by Somerton and Turner (1974); Cohen, Gross, and Haring (1976); Fredericks, Riggs, Furey, Grove, Moore, McDonnell, Jordan, Hanson, Baldwin, and Wadlow (1976); Fredericks, Baldwin, Grove, Riggs, Furey, Moore, Jordan, Gage, Levak, Alrick, and Wadlow (1979); Connor, Williamson, and Siepp (1978); and Shearer, 1972.

The Pennsylvania Training Model (Somerton \& Turner, 1974; Somerton \& Meyers, 1976; Meyers, Sinco, \& Stalma, 1973) is a good example of a comprehensive developmental curriculum. Its first component is an Assessment Guide, a general assessment that yields an overview of the child's development. The Guide is 
followed by the major portion of the curriculum, consisting of sequential behavior lists of 14 domains that clearly reflect content areas of importance for the severely handicapped. Individual sequences contain from six items (nasal hygiene) to 80 items (feeding-drinking) organized as checklists. The behaviors are subjectively rated in assessment as (0) $0 \%$ correct response, (1) moderate competency, (2) adequate competency, or (3) complete competency. Sample items from the feedingdrinking domain (Somerton \& Turner, 1974, pp. 19, 21) illustrate the fine increments among the sequenced behaviors, as well as the comprehensiveness of the curriculum:

\section{Child opens mouth when physically} stimulated.

2. Child closes mouth when physically stimulated.

3. Child takes fluid from a dropper while in a reclining position.

4. Child retains liquid in mouth without dribbling.

78. Child pierces food using fork independently.

79. Child brings fork with piece of food on it to mouth.

80. Child returns empty fork to bowl or plate.

Behavior checklists in the Pennsylvania Training Model are followed by the third component, a sample of a systematic program and an example of its modification following a period of training. The sample program is written on an individual Prescriptive Planning Sheet that specifies the antecedents, behavior, consequences, and criteria. The fourth component of the curriculum manual consists of two examples of simple data charts to monitor progress. Finally, a flow chart mapping implementation of the total model is presented as a summary of the developmental curriculum process.

The Pennsylvania Training Model is fairly representative of developmental curricula for the severely handicapped. Cohen, Gross, and Haring (1976) have presented a more comprehensive compilation of developmentally sequenced behaviors, drawing from 24 previously published scales. Some activity suggestions and explanations for each content domain are included. The curriculum by Shearer (1972) provides, in addition to behavior checklists, many activities for training. A box of activity cards matched to each item (and cross-referenced to related items) complements the checklists.

Fredericks et al. $(1976,1979)$ and Bald win (1976) have developed a curriculum that combines task analysis (discussed in the following section) with the developmental model. Skills in the checklists are first broadly task analyzed as "phases," and then broken down into very small "steps" of behavior. It is expected that the curriculum be used only as a guide. Steps that are too detailed should be combined, and additional steps should be added (branching) to individualize the curriculum.

The four curricula that have been reviewed infer or describe skill training within content domains. A developmental model by Connor, Williamson, and Siepp (1978), however, outlines and provides examples of strategies for training objectives both within and across domains: "(a) a sequential task analysis, (b) a major activity and its possible consequences across developmental areas, (c) integrated activities meeting multiple objectives, and (d) multiple interventions to meet a general behavioral objective" (p. 275). The integration of content domains in strategies (b) and (c) is unique to this curriculum and contributes to its flexibility. Training an activity with consequences in other areas, strategy (b), emphasizes consideration for the impact of goal selection in one content area on other domains of behavior. For example, training reach and grasp may contribute to progress in self-feeding and communication board use, since both skills involve eye, hand, and arm coordination. Strategy (c) involves the training of several target objectives in a single activity, a concept that lends itself to a more natural, meaningful training situation. The Guide recommends, but does not include, normal behavior sequences for the assessment and the selection of objectives, as in other developmental curricula.

\section{Cognitive Models}

In addition to the assumptions of the traditional developmental curriculum model (the normal developmental sequence is logical; many behaviors are prerequisites; and objectives at a student's developmental level are appropriate), cognitive developmental models propose three other assumptions that reflect the theoretical orientation of Jean Piaget (Stephens, 1977; Bricker, Siebert, \& Casuso, 1980). First, objectives must be slightly beyond the present level of cognitive development to be motivating. In Piagetian terms, the training 
situations must create psychological "disequilibrium," or conflict, to be resolved by the student. This process of "equilibration" is deemed critical for developmental progress. A second assumption is that the student must interact with the environment if learning is to occur; the student must be active in the training program. And third, the interrelation of content domains, particularly interrelating the cognitive domain with all other domains, must be considered in selecting appropriate objectives. Cognitive development determines and constrains what can be learned in other content areas. For example, self-feeding with a spoon would not be an appropriate objective for a student who has not demonstrated the simplest levels of means-ends behaviors, because it involves understanding "tool use."

In the cognitive approach, normal sequences of development are used in the same way as previously described for assessment and selecting objectives. But an additional developmental sequence to cover the cognitive domain (as Piaget has described the sequence), such as the Ordinal Scales of Psychological Development (Uzgiris \& Hunt, 1975), is central and unique to this model.

Training targeted objectives follows behavioral meth= odology as in other developmental curricula, but special emphasis is placed on the antecedents to the target response (structuring the environment to create disequilibrium). The role of reinforcement is given less emphasis.

Overall, the developmental models (including the cognitive model) are similar to one another and primarily describe the content of instruction. Assessments and objectives for the severely handicapped come directly from normal sequences of skill acquisition. Behavioral methodology is often suggested for training targeted objectives.

\section{Concerns Raised by the Developmental Curriculum Model}

The important issue evolving from these approaches is the assumption that behavior must progress developmentally, that certain behaviors must be present in a student's repertoire before other behaviors can be acquiredeither through maturation or as a result of direct intervention. This type of developmental logic has been criticized when applied to severely and multiply handicapped children (cf., Guess, Sailor, \& Baer, 1978; Switzky, Rotatori, Miller, \& Freagon, 1979).

Criticism has been based primarily on: 1) lack of empirical data demonstrating that severely handicapped persons do follow a normal developmental sequence, due, in part, to the presence of severe sensory and motor disabilities; and 2) the fact that many curricula resulting from developmental approaches have included teaching tasks that have been neither age-appropriate nor functional for adapting to environmental realities. For example, the Pennsylvania Training Model (Somerton \& Turner, 1974) includes the following items:

\section{Child will move object held in his hand to his mouth (p. 17). \\ Child will fling ball, toy, or paper without di- rection (p. 17). \\ Child squeezes and smears pieces of finger food on table (p. 20). \\ Child plays in bathroom sink by keeping hands under water (p. 27).}

These examples, although exaggerated, illustrate a general concern that severely handicapped students are not always being taught the types of skills that will enable them to interact with their present and future environments. As a result, a major effort has been launched to provide more practical instructional programs for severely handicapped students, requiring direct intervention in deficit skill areas. Not coincidentally, this effort has paralleled the emergence of environmental adaptation approaches, including behavioral analysis, as a dominant influence in instructional programming for severely handicapped students.

\section{ENVIRONMENTAL ADAPTATION APPROACHES}

\section{Behavioral/Remedial Approach: Developing a Technology for "How to Teach"}

Starting in the mid-1960s, applied behavior analysis began to have a major impact on curriculum and, particularly, instructional approaches used with severely handicapped students. Behavioral techniques such as shaping, fading, prompting, and reinforcing were introduced within special education in the attempt to teach severely handicapped students a variety of skills. Skills ranged from self-help to the more complex areas of speech and language. These techniques and procedures were presented primarily by behavioral psychologists who were well versed in the operant analysis of behavior. They also combined instructional procedures with a variety of experimental designs (Baer, Wolf, \& Risley, 1968; Hersen \& Barlow, 1976) aimed at demonstrating the controlling effects of consequences on behavior. 
The term remedial was soon combined with behavioral to indicate that skills could be taught where none before had existed and that the individual's developmental levels could be minimized when selecting skills targeted for training. Parallel behavior modification techniques were also used among severely handicapped persons to decrease undesirable behaviors. For some cases, professionals perceived a need to eliminate undesirable behavior among severely handicapped persons before attempting to teach new, more adaptive skills. This clinical approach was a derivation of earlier studies in behavior modification that concentrated mainly on the reduction of behavioral deviancies among emotionally disturbed or psychiatric populations (Ullmann \& Krasner, 1965). This orientation is still present in many treatment/education programs for severely handicapped persons (cf., Browning, 1980).

The major direction taken in the behavioral approach, however, was to further develop and refine the instructional technology for teaching numerous skills to severely handicapped persons. This was accompanied by an attempt to relate the technology more directly to the field of special education, including classroom instruction and vocational training. One major outcome of this effort was the heavy emphasis on task analysis procedures.

Behaviorists, along with special educators, had become convinced that almost any skill could be taught via operant procedures, if the task could be broken down into sufficiently small (and obtainable) units of behavior. When failures to teach a skill did occur, it was assumed that the task was not broken down sufficiently for the student or that the instructional procedures were not being applied correctly. Some investigators (Gold, 1972; Gold \& Pomeranz, 1978) assumed that carefully constructed task analyses were sufficient motivation to result in learning.

What followed was a proliferation of task breakdowns for a multitude of skills that might be taught to severely handicapped students. The 1,008-page volume by Anderson, Hodson, and Jones (1974) is an obvious example. Task breakdown was followed by specific information on how to task analyze a skill in preparation for instructional programming (cf., Belmore \& Brown, 1978; Cuvo, 1978).

The task analysis approach has been valuable to the extent that it has focused attention on the need to identify behavior in observable units that lend themselves to direct remediation efforts. It has also resulted in identifying many skills that can and should be taught to persons with severe handicapping conditions to enable them to lead more productive, independent lives.
A recent concern, however, is that the systematic, methodical task analysis approach might actually slow down progress for more capable students by taking them through unnecessary training steps (Liberty \& Wilcox, 1981a). Another earlier concern was that the task analysis approach was not, by itself, sufficient to teach many skills to severely handicapped students. This concern stimulated the development of even more precise instructional procedures designed to enhance the learning of a skill once it had been broken down into small units of behavior.

These instructional procedures included, for example, the Project MORE model that delineates levels of assistance in teaching a specific response (Lent, 1979; Lent \& McLean, 1976) and the delayed prompt procedures that specify increasing time intervals (in seconds) between the presentation of a stimulus and either the selfinitiated or, if necessary, the teacher-prompted response to be made by the student (Snell \& Gast, 1981). Use of stimulus fading or errorless learning would also fit into this effort to further refine the instructional technology available toward educating severely handicapped students (Touchette, 1971; Schreibman, 1975; Holvoet, 1978).

The more sophisticated procedures have proven to be effective with many severely handicapped students. Skills have been acquired where none have existed before. Instructional procedures have been, in large part, shown to be responsible for learning - at least learning that could be demonstrated in the specific instructional setting, which often required 1:1 training. This latter qualification is important.

A common finding has been that learning occurring under tight instructional control does not necessarily generalize to other persons, settings, or materials. This is significant to the education and treatment of severely handicapped students. Newly taught skills will be of little value to the learner if they do not occur in more natural situations and environments. The findings prompted design and development of a new technology to teach generalization in the majority of situations in which it did not occur spontaneously. A frequently cited paper by Stokes and Baer (1977) identified many common and useful procedures for teaching generalization. This additional technology has been viewed as a necessary extension to the education and training of severely handicapped students. Generalization training has attempted to correct original deficiencies in the behavioral approach by adding training requirements to the education process for severely handicapped students.

In retrospect, the behavioral approach has spawned, over the past few years, a sophisticated, how-to-teach 
technology for severely handicapped students. Continued refinements have increased the complexity. In some respects, the technical nature of many of the procedures has reached a point at which, because of time limitations, teachers will be unable to implement them consistently or effectively in the everyday classroom environment. This situation has been aptly expressed by Liberty and Wilcox (1981a) in their cautions about the overuse of task analysis.

\begin{abstract}
In the course of their education, most professionals have been trained to perform countless acts of reductionism on a variety of tasks. We are all too familiar with the 76-step task analysis of how to thread a needle, the 42-step analysis of shoe tying, or the 26-step breakout of how to fasten a seat belt. However, once teachers are faced with classrooms of pupils, such detailed task analysis is frequently left behind. (p. 1)
\end{abstract}

Each new development in the expanding technology leaves less room for additional considerations, because the procedures accruing to the technology are so time consuming that none remains to pursue other approaches. Slavish adherence to a strict behavioral technology, in its narrowness, carries the danger of blocking discovery of other important concepts in teaching severely handicapped students.

A more serious question concerns whether or not the behavioral approach accurately represents a total methodology for changing behavior among severely handicapped persons. Since it probably does not, should the procedures derived from it be used exclusively as the technology of choice? Some indications have already been manifested that strict, exclusive adherence to a behavioral model may have fostered how-to-teach practices that are not conducive to the most effective intervention efforts. Some of these practices and concerns are discussed below.

\section{Splinter Skill Training}

In the zeal to demonstrate that many skills can be taught in the absence of developmental prerequisites, behaviorists have tended to teach skills in isolation (teaching content areas separate from one another). Thus, a student might be taught speech at one time, how to dress at another time, and so on. In many cases, the complicated task analyses for specific training programs preclude simultaneous teaching of other skills that require similarly complicated instructions.

As a result of teaching splinter skills in relatively isolated times and settings, generalization to other persons, places, and settings has not always taken place. As already pointed out, this dilemma prompted the design and development of new procedures to teach the generalization of skills. A whole new technology was required to overcome a limitation of the original technology. The problem might have been averted if behaviorists had initially recognized the interdependence of behavior and skills across and within content domains, as was suggested earlier by some developmental approaches (e.g., Connor et al., 1978).

\section{Nonfunctional Training}

Those advocating a behavioral approach have correctly pointed out that many developmentally oriented curricula did not teach functional skills. But behavioral programs have often fallen into the same trap. This is pointed out not so much to direct criticism to the procedures per se as it is to the types of training tasks to which the procedures have led. Behavioral procedures such as response shaping and stimulus fading have been conducted most effectively in massed trial sequences; the same response is emitted over and over again during the session. This format allows the teacher or therapist to build (or shape) the behavior in the desired direction gradually.

On the surface, this format seems logical since learning among severely handicapped students is, at best, slow. But the training outcome, when successful, is often so specific to the training sessions that spontaneous, functional use of the skill is never demonstrated. Indeed, the tasks themselves are often not functional. Teaching a child to raise his or her hand in imitation training, for example, is of dubious value in the real world. We are reminded here of an earlier caution by Wolfensberger (1972) that the means of instruction should be just as normalizing as the ends of the instruction.

One might also add to the discussion here the use of nonfunctional and artificial reinforcers (e.g., foods, liquids, tokens) to maintain an acceptable response rate during mass-trial training. Too frequently, attempts are not made to fade out these reinforcers, or to pair them with more functional and less artificial ones. As a result, the continued use of artificial reinforcers reduces generalization of the training skill to natural environments where these reinforcers are not present. A similar problem exists with the substantial number of severely handicapped students for whom reinforcers are not easily identified (or the reinforcers are so transient that they prove to be nonfunctional for purposes of training). In these cases, the end objective of training is frequently lost to the means - trying to find reinforcers for the student. 


\section{Explaining Failures}

The literature abounds with published reports that demonstrate the effective use of behavioral procedures in teaching severely handicapped students a variety of useful skills, but probably an equal number of efforts were not successful (and likely not published). Guess, Sailor, and Baer (1978) have reported that approximately 40 percent of their subjects failed to acquire rudimentary motor and vocal imitation skills in two years of extensive training that used the best behavior modification techniques available.

How can one account for the high number of students who did not learn? One explanation is that the technology is far from complete and that better instructional procedures will eventually be designed. Another explanation is that those students did not have the prerequisite skills necessary for learning the type of imitation behavior being taught. This explanation seems more plausible in view of research that has demonstrated certain developmental prerequisites for speech and language skills among severely and profoundly retarded individuals (Kahn, 1975; Leonard, 1978; Lobato, Barrera, and Feldman, 1981).

Thus, the danger exists that some behavioral procedures will be used unsuccessfully when learning is not going to occur unless other skills are also acknowledged as prerequisites, and when other approaches might provide better results. Umbreit (1980), for example, has presented some tentative data suggesting that severely handicapped students acquire skills at a faster rate (fewer number of trials to criterion) when they are developmentally rather than randomly sequenced.

The behavioral approach, in summary, has offered much to the education and training of severely handicapped persons. It has provided many teaching techniques and procedures that should be a part of instructional programming for this population of students, and it has given us a scientific methodology for evaluating and assessing educational intervention efforts. As a comprehensive instructional model, however, it has many limitations. If the training procedures and techniques are viewed as a total and uncompromising explanation of human learning; the potential benefactors of that technology might not have received the best training we are capable of developing. If the behavioral approach is applied judiciously, though, it may reap positive benefits.

\section{Community Adaptation Approach: Selecting Criteria for "What to Teach"}

The behavioral approach has not dealt adequately with the issue of "what to teach" or the more funda- mental considerations of an integrated, functional curriculum for severely handicapped students. This is likely due in part to the underlying premise that skills can be taught as separate entities if only they are appropriately task analyzed, as well as the reluctance among behaviorists to pursue a more "holistic" approach that fully acknowledges the interdependence among skill domains. The same criticism can be directed at some developmental approaches that both assess and treat behavior deficiencies as isolated units - e.g., teaching motor skills separate from cognitive skills, teaching speech skills separate from cognitive or motor skills.

The behavioral approach did direct attention toward teaching more functional and age-appropriate skills to severely handicapped students. It did not, however, provide any systematic guidelines or rationale for what was to be taught. In the mid 1970s Lou Brown and his colleagues at the University of Wisconsin introduced conceptual systems, or rationale, for designing and organizing curriculum content for severely handicapped students. The impetus for this movement was heavily influenced by a developing philosophy of "normalization" - that severely handicapped persons should be integrated into community life and that they should be prepared, as much as possible, for normal existence in the mainstream of society (Wolfensberger, 1972). Educators, then, had the challenge of initiating curriculum strategies that would enable severely handicapped students to learn a myriad of skills necessary for successfully adapting to the community - as contrasted with teaching skills to prepare them to live in segregated environments and facilities.

In an early publication, Brown, Nietupski, and HamreNietupski (1976) referred to the "criterion of ultimate functioning" as a standard by which classroom curriculum content should be measured for severely handicapped students. This concept "refers to the ever changing, expanding, localized, and personalized cluster of factors that each person must possess in order to function as productively and independently as possible in socially, vocationally, and domestically integrated community environments" (p. 8). They posed six questions for the classroom teacher and other service delivery personnel to consider before initiating education and treatment activities:

1. Why should we engage in this activity?

2. Is this activity necessary to prepare students to ultimately function in complex heterogeneous community settings?

3. Could students function as adults if they did not acquire the skill?

4. Is there a different activity that will allow students to approximate realization of the criterion of ultimate functioning more quickly and more efficiently? 
5. Will this activity impede, restrict, or reduce the probability that students will ultimately function in community settings?

6. Are the skills, materials, tasks, and criteria of concern similar to those encountered in adult life? (p. 9)

Given the premise that the curriculum content for severely handicapped students should evolve around teaching skills for eventual community living, the next step taken by the Madison group was to develop strategies to identify skills that should be taught. These strategies were discussed in papers by Brown, Branston, Hamre-Nietupski, Pumpian, Certo, and Gruenewald (1979) and Brown, Branston-McClean, Baumgart, Vincent, Falvey, and Schroeder (1979). The latter publication presented workable guidelines for developing chronological age-appropriate curricular content for severely handicapped adolescents and young adults.

This strategy basically follows an ecological approach to the identification of important skills. These include domestic skills, vocational training, use of leisure and recreational activities, and skills necessary for community living. First, important skills in natural environments (e.g., group homes) and subenvironments within the larger settings (e.g., kitchens within group homes) were to be identified. Next, activities within the subenvironments necessary for community living (e.g., cooking, washing dishes) would be identified, followed by a breakdown of specific responses necessary for engaging in the identified activities. Procedures for delineating the specific skills essentially would follow a task analysis approach, as described by Belmore and Brown (1978). In the final phase, the appropriate skills targeted for remedial training would be taught.

The most significant contribution of the curriculum development strategy summarized by the two Brown et al. studies in 1979 is the emphasis placed on teaching functional, chronological-age-related skills necessary for successful interactions in domestic, community, and vocational settings. These strategies, using an ecological inventory approach, provide specific direction and rationale for selecting and organizing curriculum content for severely handicapped students, especially those of an older age level who are being prepared for "ultimate functioning" in community settings.

\section{Criteria of the Next Educational Environment}

The "criterion of ultimate functioning" (Brown et al., 1976) has been difficult to apply to infant and preschool children with severely handicapping conditions because instructional objectives derived from this concept would be so distant (temporally) that they would be irrelevant and essentially nonfunctional. Therefore, the principle was extended downward as the "criteria of the next educational environment" - the public school kindergarten. The logic of this principle implies that the curriculum for young severely handicapped preschool children should be directed toward teaching the skills necessary for successful placement in kindergarten classrooms in public school settings. This approach, described by Vincent, Salisbury, Walter, Brown, Gruenewald, and Powers (1980), is based on their research and observations suggesting that "survival skills" (social and behavioral) are more critical than academic skills in determining the success or failure of child ren as they are placed in kindergarten settings. Survival skills consist of behaviors such as compliance, attending, social interaction, and following directions.

Vincent and her colleagues (1980) are presently engaged in strategies to identify skills necessary for successful kindergarten placement. When identified, these skills will be used as the instructional objectives comprising the curriculum content to be used with severely handicapped preschool children.

Vincent et al. pointed out that in addition to identifying survival skills as a critical content domain in infant and preschool programs, the criteria of the next educational environment have implications for instructional methodology. They maintain that the precision teaching that characterizes instructional methodology for severely handicapped students does not occur in regular kindergarten classes. Thus, as suggested earlier, instructional technology for the severely handicapped may be moving beyond practical application in contemporary classroom settings and other environments that serve them.

Two ways to modify the instructional environment of special education in consideration of the next environment, as suggested by Vincent et al., are: 1) gradual modification of the special education environment to approximate the kindergarten, and 2) modification of the special education teacher's behavior to approximate the regular kindergarten teacher's behavior.

The positions taken by Brown and his colleagues and Vincent and her colleagues have made a significant contribution to the design and development of curricula for severely handicapped students. Their guidelines and curriculum selection strategies have offered to the field a functional rationale for deciding "what to teach." Accordingly, the "criterion of ultimate functioning" and the "criteria of the next educational environment" provide ecological assessments of what should be taught to severely handicapped students, based on selecting functional and chronologically age-appropriate skills. When 
the skills to be trained have been identified, the next step is to locate programs designed to teach them. As mentioned in the "how to teach" section, a seemingly endless number of already task-analyzed instructional programs is available from which to choose.

The rationale followed by Brown et al. and Vincent et al. implies that, to a large extent, curriculum development can be separated from instructional methodology for severely handicapped students. This is based on earlier observations in this article that behavioral methodology was a major influence in the development of specific instructional programs, rather than the programs, per se, playing a major role in the design of instructional procedures and techniques. The behavioral technology led to development of splinter skill training programs, most of which served to further isolate content areas. Also, they utilized instructional procedures that eventually led to unacceptable levels of "reductionism."

We believe that the ecological inventory approach advocated by Brown et al. and Vincent et al. provides somewhat more effective means with which to select training objectives. We further believe, however, that it does not lead to the interdependent development of skills across and within content domains.

\section{TEACHING FUNCTIONAL SKILL CLUSTERS: A HOLISTIC APPROACH}

We contend that at least two important considerations must be addressed in future curriculum development efforts for severely handicapped students. These include: 1) teaching interdependent skills across and within content domains, and 2) a more integrated relationship between instructional procedures and educational (curriculum) objectives.

\section{Teaching Skill Clusters}

Our original concern with many developmental curricula, and with the splinter skill teaching approach evolving from a behavioral technology, was the underlying assumption that behavior consists of isolated responses that can be taught separate and independent from one another. We also were concerned about the disregard for functional interdependence between and among content domains. An earlier reaction to the developmental approach was the frequent omission of teaching functional, age-appropriate skills to severely handicapped students. This resulted in a plethora of care- fully designed instructional programs for teaching relevant and ecologically useful skills (e.g., how to ride a bus, make change, go shopping, wash dishes, hold the head up, reach for objects, etc.)

In the rush to teach relevant and useful skills, and to construct procedures for identifying what should be taught, an equally obvious point may have been overlooked: Optimal adaptation to the environment requires the person to emit many behaviors almost simultaneously. Ecologists often refer to the "stream of behavior" as the organism interacts with the environment. Developmental psychologists and others frequently refer to treating the "whole child." As Sailor and Guess (in preparation) have pointed out, "Regardless of one's particular theoretical persuasion, the message is the same; the person must learn to emit many different types of actions either concurrently or in rapid succession if adaptive behavior is to occur."

Present educational efforts with severely handicapped students involve teaching skill areas that have no centrally unifying basis. This forces us into a situation in which we must attempt to teach a likely unobtainable number of discrete skills to achieve even the beginnings of effective adaptive behavior. With these technologies, severely handicapped students simply do not have the time to learn all the skills necessary for adequate functioning in the school, home, or community.

We propose instead that educational programming for the severely handicapped must begin to concentrate on teaching skills that have the widest and most functional applicability across a variety of tasks and content areas. Equally important, the skill clusters taught must cut across traditional content domains. If, for example, a large number of task-analyzed instructional programs were to be lined up side by side, we might be able to identify a number of "critical skills" common across the various programs. Might it not, therefore, be better to teach severely handicapped students a variety of critical skills with specific instructional programs rather than follow the present philosophy and attempt to teach a multitude of isolated instructional programs with the hope that somewhere along the way a more generalized use of the skills will emerge?

Critical skills, as defined here, include behaviors essential to successful performance in numerous tasks, both within and across content domains. The ability to reach, grasp, and release objects, for example, would be critical skills for many self-help, play, and vocational tasks. The ability to discriminate between objects and events would be equally essential for the above tasks, as well as for the development of academic and communication skills. We are not here advocating the teaching of 
skills in isolation with the anticipation that these skills will spontaneously emerge within the context of more functional tasks. This approach has failed in the past. We are advocating, rather, the selection of age-appropriate and functional tasks that include common critical skills that will more rapidly generalize to new instructional programs. Current approaches attempt to teach too many tasks consisting of skills that are situationspecific, and yet require excessive amounts of instructional time.

At present, developmental assessment instruments may be needed to help identify critical skill deficiencies. If so, the deficiencies have to be translated into ageappropriate and functional objectives, with instructional programs directed toward development of the identified critical skills. This requires the caution that severely handicapped students might not always exactly follow a developmental sequence, especially severely handicapped students who have accompanying motor and sensory disabilities.

The holistic approach would provide the beginnings of a unified rationale for selecting curriculum content based on a sequence of development. It would provide for the teaching of functional and age-appropriate skills. At the same time, it would avoid the present tendency to attempt to teach skill areas as isolated units with minimal concern for prerequisite skills or the overall amount of instructional time required to attain competency.

If one agrees that critical skills should be taught in place of numerous prepackaged instructional programs, the next concern involves a conceptual framework for teaching these skills. Within this context, we advocate the teaching of skill clusters, defined as a grouping of environmentally appropriate and functional behaviors that cut across typical content domains. This assumes that motor, language, cognitive, and social skills are best taught as interdependent clusters.

A series of articles from the University of Kansas (Mulligan, Guess, Holvoet, \& Brown, 1980; Holvoet, Guess, Mulligan, \& Brown, 1980; Brown, Holvoet, Guess, \& Mulligan, 1980) has described a procedure for teaching skill clusters. These articles describe an individualized curriculum sequencing model (ICS) designed to teach skill clusters that combine content areas. A young child might be taught, for example, to look at an object (visual orientation), raise his/her head (gross motor), produce a sound (communication), reach out and grasp the object (fine motor), and then use the object in the appropriate manner (cognitive and motor). This short skill cluster would logically contain skills determined from the child's assessed developmental level, and skills that would enable the child to better interact with his/her environment in an age-appropriate, functional manner. For a young child, the objects in the example might be favorite toys; for an older profoundly retarded student, the objects might be a hair brush, radio, or pencil sharpener.

The ICS model systematically teaches the student to combine skills across content domains and to perceive the relationship between them. In contrast, a more traditional program presents the student with repeated trials for each component of the sequence, separately and independently from one another - and frequently preceded by the verbal directive, "hands in lap."

The analogy can be extended to self-contained instructional programs. One program might teach a student to make change, another to make purchases, and still another to ride a bus to the store. Might it not be better to teach the student all these skills simultaneously? The instructional time may be longer, but in the end the student would have learned a number of interrelated skills germane to the ultimate objective of independent shopping.

This approach of teaching critical skills that traverse content domains will require a basic readjustment of current programming efforts. We must be willing to sacrifice the convenience of prepackaged, task-analyzed instructional programs and start designing and developing programs that effectively interrelate traditional content areas in a more holistic manner. We must be willing to forego the temptations of splinter skill training and undertake the more difficult task of identifying and teaching interdependent critical skills that ultimately will lead to a more naturalized, cohesive instructional program.

\section{Instructional Procedures and Educational Objectives}

Within recent years, instructional technology has often been separated from curriculum development in general and from individual education objectives specifically. It has possibly come to the point where the "tail is wagging the dog." A similar observation has recently been made by Liberty and Wilcox (1981b) when they stated:

The objectives of education, the needs of the individual learner, and even common sense have been supplanted by a superstitious and slavish adherence to certain procedures which have been sanctified in the name of systematic instruction and behavioral technology. The procedures of instruction have become more important than the aim of instruction. (p. 2) 
A more holistic approach to the education of severely handicapped students can potentially instill new life in the design and development of instructional procedures for this population. In starting to move away from the overuse of prepackaged instructional programs designed to teach splinter skills, we may begin to see more instructional options to supplement and enhance current behavioral technology. The identification of deficient critical skills among severely handicapped students and the development of training programs that traverse content domains will likely lead us to view the behavior of these students from a more complex and sophisticated level one that more fully recognizes complicated interactions between cognitive, sensory/motor, and emotional behavior. This realization will, we hope, encourage us to fit the instructional procedures to the identified needs of the student, rather than try to make any one set of instructional procedures or any one approach fit any need. For severely handicapped students, developmental, Piagetian, behavioral, and other approaches may be useful in implementing education and treatment programs.

The important point is that the curriculum objectives must determine, to a large extent, the instructional procedures to be used, rather than vice versa, and that we must become more amenable to using and developing new instructional procedures in the education and treatment of severely handicapped students. This does not imply that we should abandon our current methodology, which requires the systematic collection and analysis of data resulting from intervention efforts. To the contrary - developing and using new instructional procedures and approaches will require an even heavier emphasis on program evaluation for both individual students and groups of students.

\section{SUMMARY}

We have described the development of instructional procedures and curricula for severely handicapped students over the past decade. Few would dispute the statement that gains in educating this population have been impressive. The field has come a long way in a relatively short time. Changes are needed, however, if this momentum is to be maintained, and we must seriously reevaluate where our predominant behavioral technology is taking us.

We have argued that the present technology is leading to a not entirely useful level of reductionism, approaching a point at which the technology is neither practical to implement in most classroom settings nor necessarily desirable even if we could do so. We have suggested that future efforts to develop instructional procedures and curricula for severely handicapped students should explore new approaches including, especially, those that teach critical skills across and within content areas, as well as approaches that more fully recognize the inherent complexity of these students' learning needs.

\section{REFERENCES}

Allen, K. E. Early intervention for young severely and profoundly handicapped children: The preschool imperative. AAESPH Review, $1978,3,30-41$.

Anderson, D. R., Hodson, G. D., \& Jones, W. G. (Eds.). Instructional programs for the severely handicapped student. Springfield, IL: Charles C Thomas, 1974.

Baer, D. M., Wolf, M. M., \& Risley, T. R. Some current dimensions of applied behavior analysis. Journal of Applied Behavior Analysis, 1968, 1, 91-97.

Baldwin, V. L. Curriculum concerns. In M. A. Thomas (Ed.), Hey, don't forget about me! Reston, VA: Council for Exceptional Children, 1976, pp. 64-73.

Belmore, K. J., \& Brown, L. A job skill inventory strategy designed for severely handicapped potential workers. In N. Haring \& D. Bricker (Eds.), Teaching the severely handicapped (Vol. 2). Seattle: American Association for the Education of the Severely/Profoundly Handicapped, 1978, pp. 223-262.

Bricker, D., Bricker, W., Iacino, R., \& Dennison, L. Intervention strategies for the severely and profoundly handicapped child. In N. G. Haring \& L. J. Brown (Eds.), Teaching the severely handicapped (Vol. 1). New York: Grune \& Stratton, 1976.

Bricker, D. D., Dennison, L., \& Bricker, W. A. A language intervention program for developmentally young children. Mailman Center for Child Development Monograph Series, No. I. Miami: University of Miami, 1976.

Bricker, D., Seibert, J., \& Casuso, V. Early intervention. In J. Hogg \& P. Mittler (Eds.), Advances in mental handicap research. New York: John Wiley \& Sons, 1980.

Brown, F., Holvoet, J., Guess, D., \& Mulligan, M. The individualized curriculum sequencing model (III): Small group instruction. Journal of the Association for the Severely Handicapped, 1980, 5, 352-367.

Brown, L., Branston, M. B., Hamre-Nietupski, S., Pumpian, I., Certo, N., \& Grunewald, L. A strategy for developing chronological age appropriate and functional curriculum content for severely handicapped adolescents and young adults. Journal of Special Education, 1979, 13, 81-90.

Brown, L., Branston-McClean, M. B., Baumgart, D., Vincent, L., Falvey, M., \& Schroeder, J. Using the characteristics of current and subsequent least restrictive environment as factors in the development of curricular content for severely handicapped students. Journal of the Association for the Severely Handicapped, $1979,4,407-424$.

Brown, L., Nietupski, J., \& Hamre-Nietupski, S. Criterion of ultimate functioning. In M. A. Thomas (Ed.), Hey, don't forget about me! Reston, VA: Council for Exceptional Children, 1976, pp. 2-15.

Browning, R. M. Teaching the severely handicapped child: Basic skills for the developmentally disabled. Boston: Allyn \& Bacon, 1980.

Cohen, M., Gross, P., \& Haring, N. G., Developmental pinpoints. In N. G. Haring \& L. J. Brown (Eds.), Teaching the severely handicapped (Vol. 1). New York: Grune \& Stratton, 1976.

Connor, F. P., Williamson, G. G., \& Siepp, J. M. Program guide for infants and toddlers with neuromotor and other developmental disabilities. New York: Teachers College Press, 1978.

Cuvo, A. Validity task analysis of community living skills. Vocational Evaluation and Work Adjustment Bulletin, 1978, 11, 13-21. 
Folio, R. \& DuBose, R. F. Peabody developmental motor scales. Nashville: Institute on Mental Retardation and Intellectual Development, George Peabody College for Teachers, 1974.

Fredericks, H. D., Baldwin, V. L., Grove, D. N., Riggs, C., Furey, V., Moore, W., Jordan, E., Gage, M. A., Levak, L., Alrick, G., \& Wadlow, M. A data-based classroom for moderately and severely handicapped (3rd ed.). Monmouth, OR: Instructional Development Corp., 1979.

Fredricks, H. D., Riggs, C., Furey, T., Grove, D., Moore, W., McDonnell, J., Jordan, E., Hanson, W., Baldwin, V., \& Wadlow, M. The teaching research curriculum for moderately and severely handicapped. Springfield, IL: Charles C Thomas, 1976.

- Gentry, D., \& Adams, G. A curriculum-based direct intervention approach to the education of handicapped infants. In N. G. Haring \& D. D. Bricker (Eds.), Teaching the severely handicapped (Vol. 3). Seattle: American Association for the Education of the Severely/Profoundly Handicapped, 1978.

Gold, M. W. Stimulus factors in skill training of the retarded on a complex assembly task: Acquisition, transfer, and retention. American Journal of Mental Deficiency, 1972, 76, 517-526.

Gold, M. W., \& Pomeranz, D. J. Issues in prevocational training. In M. E. Snell (Ed.), Systematic instruction of the moderately and severely handicapped. Columbus, OH: Charles E. Merrill, 1978, pp. 431440 .

Guess, D., Sailor, W., \& Baer, D. M. Children with limited language. In R. L. Schiefelbusch (Ed.), Language intervention strategies. Baltimore: University Park Press, 1978, pp. 101-144.

Haring, N. G., \& Bricker, D. Overview of comprehensive services for the severely/profoundly handicapped. In N. G. Haring \& L. J. Brown (Eds.), Teaching the severely handicapped (Vol. 1). New York: Grune \& Stratton, 1976.

Hayden, A. H., McGinness, G., \& Dmietriev, V. Early and continuous intervention strategies for severely handicapped infants and very young children. In N. G. Haring \& L. J. Brown (Eds.), Teaching the severely handicapped (Vol. 1). New York: Grune \& Stratton, 1976.

Hersen, M., \& Barlow, D. H. Single case experimental designs: Strategies for studying behavior change. New York: Pergamon Press, 1976.

Holvoet, J. Some general observations about errorless training and some examples of errorless programs used with SMH individuals. Unpublished paper, University of Kansas, 1978.

Holvoet, J., Guess, D., Mulligan, M., \& Brown, F. The individualized curriculum sequencing model (II): A teaching strategy for severely handicapped students. Journal of the Association for the Severely Handicapped, 1980, 5, 337-351.

Kahn, J. Relationship of Piaget's sensorimotor period to language acquisition in profoundly retarded children. American Journal of Mental Deficiency, 1975, 79, 640-643.

Lent, J. R. Systematic skill training. Unpublished paper, George Peabody College for Teachers of Vanderbilt University, Project Change, 1979.

Lent, J. R., \& McLean, B. M. The trainable retarded: The technology of teaching. In N. G. Haring and R. L. Schiefelbusch (Eds.), Teaching special children. New York: McGraw-Hill, 1976.

Leonard, L. Cognitive factors in early linguistic development. In R. Schiefelbusch (Ed.), Bases of language intervention. Baltimore: University Park Press, 1978.

Liberty, K., \& Wilcox, B. Forum: Slowing down learning. Association for the Severely Handicapped Newsletter, 1981, I(2), 1-2.(a)
Liberty, K., \& Wilcox, B. Forum: Abuse and misuse of systematic instruction and behavior technology: The rabbit test. Association for the Severely Handicapped Newsletter, 1981, 7(4), 1-2.(b)

Lobato, D., Barrera, R. D., \& Feldman, R. S. Sensorimotor functioning and prelinguistic communication of severely and profoundly mentally retarded individuals. American Journal of Mental Deficiency, 1981, 85, 489-496.

Meyers, D. G., Sinco, M. E., \& Stalma, E. S. The right to education child. Springfield, IL: Charles C Thomas, 1973.

Mulligan, M., Guess, D., Holvoet, J., \& Brown, F. The individualized curriculum sequencing model (I): Implications from research on massed, distributed, or spaced trial training. Journal of the Association for the Severely Handicapped, 1980, 5, 325-336.

Sailor, W., \& Guess, D. Curriculum sequencing. In W. Sailor \& D. Guess, Instructional design for the severely handicapped. Boston: Houghton Mifflin, in preparation.

Schreibman, L. Effects of within-stimulus and extra-stimulus prompting on discrimination learning in autistic children. Journal of Applied Behavior Analysis, 1975, 8, 91-112.

Shearer, D. The Portage guide to early education. Portage, WI: Cooperative Educational Agency No. 12, 1972.

Snell, M., \& Gast, D. Applying delay procedure to the instruction of the severely handicapped. Journal of the Association for the Severely Handicapped. 1981, 6, 3-14.

Somerton, M. E., \& Myers, D. G. Educational programming for the severely and profoundly mentally retarded. In N. G. Haring \& L. J. Brown (Eds.), Teaching the severely handicapped (Vol. 1). New York: Grune \& Stratton, 1976.

Somerton, M. W. \& Turner, K. D. Pennsylvania training model individual assessment guide. Harrisburg, PA.: Pennsylvania Department of Education, 1974.

Stephens, B. A Piagetian approach to curriculum development for the severely, profoundly, and multiply handicapped. In E. Sontag (Ed.), Educational programming for the severely and profoundly handicapped. Reston, VA.: Council for Exceptional Children, 1977.

Stokes, T. F., \& Baer, D. M. An implicit technology of generalization. Journal of Applied Behavior Analysis, 1977, 10, 341-367.

Switzky, H., Rotatori, H. A. F., Miller, T., \& Freagon, S. The developmental model and its implications for the severely/profoundly handicapped. Mental Retardation, 1979, 17, 167-170.

Touchette, P. E. Transfer of stimulus control: Measuring the moment of transfer. Journal of Experimental Analysis of Behavior, 1971, $15,347-354$.

Ullmann, L. P., \& Krasner, L. (Eds.). Case studies in behavior modification. New York: Holt, Rinehart, \& Winston, 1965.

Umbreit, J. Effects of developmentally sequenced instruction on the rate of skill acquisition by severely handicapped students. Journal of the Association for the Severely Handicapped, 1980, 5, 121-129.

Uzgiris, I. C., \& Hunt, J. Assessment in infancy: Ordinal scales of psychological development. Chicago: University of Illinois Press, 1975.

Vincent, L. J., Salisbury, C., Walter, G., Brown, P., Gruenewald, L. J., \& Powers, M. Program evaluation and curriculum development in early childhood/special education: Criteria of the next environment. In Sailor, W., Wilcox, B., \& Brown, L. Methods of instruction for severely handicapped students. Baltimore: Paul $\mathrm{H}$. Brookes, 1980.

Wolfensberger, $\mathrm{W}$. The principle of normalization in human services. Toronto, Canada: National Institute of Mental Retardation, 1972. 